\title{
THE INFECTION OF RAT TONGUE MUCOSA IN VITRO WITH FIVE SPECIES OF CANDIDA
}

\author{
JuLIE A. HOWLETT \\ Department of Oral Pathology, The London Hospital Medical College, \\ Turner Street, London E.1
}

\section{Plates XXI AND XXII}

THE pathogenesis of mucosal candidiasis has aroused much interest in recent years and several studies have revealed the morphological relationship between Candida albicans and the host epithelium in experimental infections of animal mucosa (Taschdjian, Reiss and Kozinn, 1960; Jones and Adams, 1970; Jones and Russell, 1973) and in human oral candidiasis (Cawson and Rajasingham, 1972). While such studies have demonstrated the host-parasite relationship of established fungal infection, investigations into the mechanisms of fungal invasion require a sequential examination of fungal entry into the tissues, which would prove tedious in animals and impracticable in human subjects.

Some reports would seem to encourage the use of organ-culture systems for studying candidal invasion. Blank et al. (1959) examined the pathogenesis of dermatophyte invasion of skin in culture, while more recently Pemberton and Turner (1973) investigated the experimental infection of human gingival mucosa in vitro with $C$. albicans. In both of these studies, similarities were demonstrated in the invasive behaviour of the fungi in vitro and in vivo. It therefore appears that organ cultures might be useful in investigating active invasion of oral epithelium by Candida. They might also provide an opportunity to study the host-parasite relationship in the absence of systemic factors, and the effect that differences in epithelial keratinisation might have on the course of fungal invasion.

In such studies it is important to establish that the tissue in culture is not merely acting as a passive growth medium in which any fungal strain, irrespective of its pathogenicity, could proliferate. To this end a comparison has been made of the activities in an organ-culture system of five species of Candida reported to have different pathogenicities (Hurley and Stanley, 1969); all have on occasion been implicated in human candidiasis (Hurley, 1966). The tissue employed in the model system was the dorsal tongue mucosa of neonatal rats, a tissue which Miles (1974) has successfully grown in culture for up to 10 days and which has also been shown to be susceptible to infection with C. albicans in vivo (Jones and Adams, 1970).

Received 7 Nov. 1975; accepted 29 Dec. 1975.

J. MED. MICROBIOL.-VOL. 9 (1976)

309 


\section{MATERIALS AND METHODS}

\section{The organ-culture system}

Tissues were obtained from decapitated Sprague-Dawley rats aged 1-3 days. Explants about $2 \mathrm{~mm}$ square were taken from the dorsal surface of the tongue as described by Miles (1974), washed initially with Tyrode's solution containing streptomycin $100 \mu \mathrm{g}$ per $\mathrm{ml}$ and penicillin 200 units per $\mathrm{ml}$, and then with nutrient medium. A chemically defined nutrient medium was used, based on Weymouth's 752/1 medium (Wellcome Reagents Ltd) modified after Melcher and Hodges (1968) and incorporating ferrous sulphate $0.45 \mu \mathrm{g}$ per ml, streptomycin $100 \mu \mathrm{g}$ per ml, penicillin 200 units per $\mathrm{ml}$, hydrocortisone sodium succinate $1 \mu \mathrm{g}$ per $\mathrm{ml}$ and ascorbic acid $300 \mu \mathrm{g}$ per $\mathrm{ml}$. The tissues were supported on small pieces of Millipore filter type HA (pore size $0.45 \mu \mathrm{m}$ ) resting on stainless steel grids of the Trowell pattern (Trowell, 1954). These were placed in small plastic culture dishes and sufficient nutrient medium was introduced to reach the platform of the grids (about $1.5 \mathrm{ml}$ ). Culture dishes were then held in plastic petri dishes containing saline-moistened filter paper to maintain a humid environment. The petri dishes were stacked in a McIntosh and Fildes' jar and incubated at $37^{\circ} \mathrm{C}$ with a gas phase of $50 \% \mathrm{O}_{2}, 5 \% \mathrm{CO}_{2}$ and $45 \% \mathrm{~N}_{2}$ for the times indicated below.

\section{Fungal organisms and preparation of inoculum}

The strains of Candida used were obtained from the Mycological Reference Laboratory (London School of Hygiene and Tropical Medicine) and were as follows: C. albicans strains 3091A (serotype A) and 3118C (serotype B); C. tropicalis strain 3111; C. krusei strain 3100; C. parapsilosis strain $3104 ;$ C. guilliermondii strain 3090 . The identification of the species was confirmed in our laboratory by sugar-fermentation tests. The isolates were stored as freeze-dried samples: during experimentation they were maintained on Sabouraud's dextrose agar. To minimise the number of organisms used to infect the explants, a fluid microinoculum, containing only a few viable yeast cells, was prepared in $1 \%$ peptone water (Oxoid Ltd, London) from fresh 24 -h cultures grown at $37^{\circ} \mathrm{C}$. The optical density of the suspension was read in a spectrophotometer (S.P. 500, Pye Unicam Ltd,) at a $400 \mathrm{~nm}$ wavelength, and the number of cells per microlitre of fluid was calculated from a standard reference curve, constructed by plotting the optical densities of different dilutions of a yeast suspension against viable counts obtained by the method of Miles, Misra and Irwin (1938). The yeast suspensions could thus be diluted to give the required number of viable cells per microlitre of fluid.

\section{Experimental infection with $C$. albicans}

The initial experiments investigated the behaviour of $C$. albicans in the culture system. Twenty-one explants were set up and 14 were inoculated approximately $4 \mathrm{~h}$ later with 5-15 yeast cells of $C$. albicans in $1 \mu \mathrm{l}$ of fluid by means of $1-\mu 1$ Microcap pipettes (Drummond Scientific App. USA), the remaining seven explants acting as uninfected controls. After inoculation, the original maintenance conditions were resumed and the tissues were harvested at intervals of $2 \mathrm{~h}$ between hours 18 and 30 , and again at $39 \mathrm{~h}$.

\section{Experimental infection with various Candida strains}

Fifty explants were set up and inoculated after either $4 \mathrm{~h}$ or $20 \mathrm{~h}$ as above with about 30 viable yeast cells of one of the following strains: C. tropicalis (13 explants); C. krusei (11 explants); C. parapsilosis (7 explants); C. guilliermondii (7 explants); C. albicans, strain 3091A (5 explants); C. albicans, strain 3118C (7 explants). The explants were then incubated under the original maintenance conditions until they were harvested at 30,37 or $45 \mathrm{~h}$ after inoculation.

\section{Histological preparation of tissues}

Specimens were fixed in neutral formol-saline solution and routinely processed for light microscopy, the sections being serially sectioned at $5 \mu \mathrm{m}$ and stained with periodic-acid-Schiff 
reagent to demonstrate the presence of Candida, and counterstained with haematoxylin or tartrazine.

\section{RESULTS \\ Assessment of uninfected control explants}

The oral mucosa from the dorsal surface of neonatal rat tongue consisted of a stratified squamous, orthokeratinising epithelium that was organised into discrete, filiform papillae showing the dual pattern of keratinisation (Farbman, 1970). These papillae were supported by a cellular connective tissue, beneath which areas of muscle fibres could be seen. Generally this structure was well maintained in vitro, as described by Miles (1974), although tissues at the edges of the explants naturally underwent some disorganisation, and slight migration of the epithelium over the exposed connective tissues occurred. Otherwise stratification of the epithelium appeared normal and mitotic figures could be observed in the basal epithelial layers at all culture periods. An accumulation of keratin squames on the surface of the explants was noticeable even after short periods of culture; this was due to the lack of abrasive removal that normally takes place in vivo. The maintenance of connective-tissue structure was more difficult to assess by light microscopy and variation in appearance of the tissues could be noticed, including occasional areas of patchy acellularity in some specimens. However this did not seem to have any deleterious effects on the overlying epithelial cells.

\section{Assessment of infection with C. albicans}

In the experiments in which inocula containing about 10 yeast cells were employed, all of the inoculated explants showed evidence of infection, and colonies of $C$. albicans were seen to grow on top of the tissues. Blastospores (Y-phase) and mycelial forms (M-phase) of the fungus were present and by $18 \mathrm{~h}$ the M-phase could be seen penetrating the superficial keratin layer. As the incubation time increased, the penetration of the tissues progressed, so that by $24 \mathrm{~h}$ fungi could be seen in the granular layer of the epithelium, by $26 \mathrm{~h}$ in the prickle-cell layer, and by $28 \mathrm{~h}$ in the basal cell layer. After $30 \mathrm{~h}$ of incubation, infection of the explants had become extensive, and by $39 \mathrm{~h}$ it was very heavy, the hyphae passing through the epithelium and deeply penetrating the connective tissues (fig. 1). The predominant fungal form present within the tissues was filamentous (M-phase), although blastospores were also seen where tissue invasion was heavy. However, the Y-phase was never present alone in any of the cell layers.

An examination of the host tissues showed that superficial invasion of the epithelium had no deleterious histological effects on the deeper tissues. Where invasion by hyphae was more extensive, some disruption of the ordered structure of the epithelium was seen. Beneath an occasional surface fungal colony a flattening of the filiform papillae seemed to occur, although this was not a feature common to all infected areas, and some irregularities of papillary architecture were also visible in control explants. In regions of very extensive 
Fungal forms

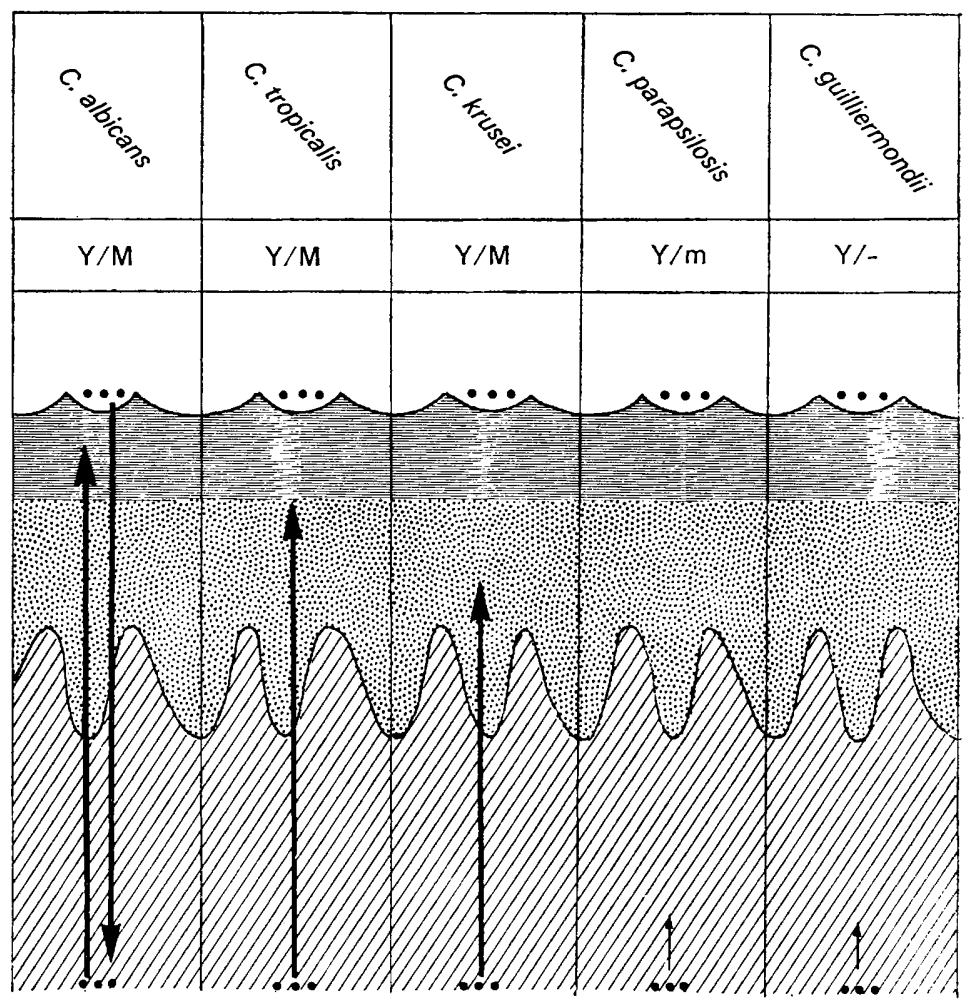

FIG. 2.-Diagram representing the spectrum of invasive activity of Candida in rat tongue mucosa in vitro. (Fungal forms: $\mathrm{Y}=$ blastospores, $\mathrm{M}=$ hyphal form, $\mathrm{m}=$ few short hyphal forms.)

invasion, as seen in specimens after 30 and $39 \mathrm{~h}$, some thinning of the epithelium was visible.

\section{Assessment of infection with Candida strains of different pathogenicities}

Histological examination showed that Candida of all five species grew well under the conditions of culture and large numbers of fungi could usually be seen growing on and around the explants, perhaps reflecting the slightly larger inoculation dose and the increased post-inoculation culture-time used in these experiments. Besides fungal growth on top of the stratum corneum there was proliferation of organisms at the edges of the explant where the connective tissues were exposed, presumably because some of the inoculum had run over the edge of the tissues. This provided the fungi with the opportunity of invading the connective tissue directly.

The general pattern of invasion by these species is summarised diagramatically in fig. 2. Explants inoculated with either strain of C. albicans showed a pattern of epithelial invasion from the surface similar to that in the previous experiment. Penetration at the edges of the explant into the connective tissue was also rapid, the fungal hyphae growing upwards through the tissues so that 
by $37 \mathrm{~h}$ penetration of all the layers of the epithelium had also occurred by fungi entering via the connective tissue. At $45 \mathrm{~h}$ the explanted tissues were completely overrun by $C$. albicans.

In the culture systems infected with $C$. tropicalis both Y-phase and M-phase were present. Heavy growth of the fungi took place on top of the epithelium but on no occasion did penetration of the stratum corneum and invasion of the deeper epithelial cell layers occur from this direction (fig. 3). However, proliferation of $C$. tropicalis from the edges of the explant occurred with striking Mphase invasion of the connective tissues. This enabled the fungus to penetrate the basement membrane and lower nucleated cells of the epithelium from below, although no penetration of the keratinised layers of the epithelium from this direction was seen. Thus, by all appearances $C$. tropicalis lacked the ability to penetrate the intact stratum corneum either from above or below.

In the tissue infected with C. kruse $i$ the fungus grew in the $\mathrm{Y}$-and $\mathrm{M}$-phases but generally showed less invasiveness than C. tropicalis. Again, despite heavy growth of the fungi on the epithelial surface, no penetration of the stratum corneum was seen. Growth into the connective tissues at the explant edges was less extensive than with the former species, and only in a few explants did $C$. krusei reach and invade the nucleated cells of the epithelium (fig. 4).

Proliferation of $C$. parapsilosis and $C$. guilliermondii took place almost entirely in the $\mathrm{Y}$-phase and only occasional short pseudohyphae were produced, mainly by $C$. parapsilosis. Active invasion of the epithelium or the connective tissue was not evident with either species (fig. 5). Despite heavy surface growth no penetration of the stratum corneum was seen, but there was sometimes flattening of the lingual papillae and possibly atrophy of the epithelium beneath the surface colonies, similar to that seen with $C$. albicans. Although only limited invasion of the connective tissue by these species occurred there seemed to be some degradation of the connective tissues in contact with colonies of blastospores at the explant edges.

\section{Discussion}

The five species of Candida used in these experiments seemed to show a gradation of invasive activities in oral mucosa in vitro. C. albicans was undoubtedly the most invasive, being able to penetrate all layers of the epithelium and connective tissue, while at the other extreme $C$. guilliermondii seemed unable to invade actively any of the mucosal tissues within the duration of the experiment. This spectrum of invasiveness in vitro reflects the pathogenicity of the fungi demonstrated in living animals (Hurley, 1966) and in kidney-cellculture systems (Hurley and Stanley, 1969). The latter workers proposed that specific aggressive mechanisms are possessed to a high degree by M-phaseproducing species such as $C$. albicans and $C$. tropicalis and only to a low degree by species such as $C$. guilliermondii in which the $\mathrm{Y}$-phase predominates. This hypothesis is clearly supported in the present studies since only $C$. albicans was able to penetrate the barrier of the stratum corneum and invade the rest of the tissues. 
Apart from invasion of the tissues, other pathogenic effects were common to all the fungal species used. These seemed to be attributable to the action of fungal metabolites within the culture system. A flattening of the lingual papillae and atrophic changes of the epithelium were often associated with heavy surface accumulation of fungi. It is interesting to note that in experimental candidal stomatitis in the monkey (Budtz-Jorgensen, 1971) atrophy of the epithelium was reported, although no intra-epithelial fungal penetration was described.

The behaviour of $C$. albicans observed in organ culture was similar to that previously reported in cultured gingival mucosa (Pemberton and Turner, 1973). The different lag times before fungal invasion starts probably reflect variations in technique and the nature of the explanted tissues. It has been shown ultrastructurally that $C$. albicans is an intracellular parasite in vivo (Montes and Wilborn, 1968; Cawson and Rajasingham, 1972) and this is also true in vitro (Howlett, 1974). Histological studies on infected cell cultures have suggested that hyphae of other Candida species are also able to enter nucleated epithelial cells (Hurley and Stanley, 1969) and this appeared to be the case with $C$. tropicalis and C. krusei, the M-phases of which penetrated the Malpighian cells in the cultured mucosa. Thus, the failure of these fungi to penetrate the stratum corneum is not indicative of a general inability to invade cells but suggests that the keratinised squames offer particular resistance to the less pathogenic Candida species. The pattern of progressive invasion seen here seems to indicate that the mucosal tissues in vitro are not merely an accumulation of cells serving as a passive growth medium for the fungi, but behave in many ways like tissue in vivo. This supports the view that the culture system is a useful experimental model in which to investigate the interaction between invading fungi and host epithelium.

One striking difference between in-vivo and in-vitro invasion of the oral mucosa by $C$. albicans is the deeper penetration of mucosal tissues seen in culture. Hyphae in mucocutaneous candidal lesions in man are confined to the superficial epithelial layers and such restricted penetration has also been reported in experimental infection of rat (Jones and Russell, 1973) and mouse mucosa (Taschdjian et al., 1960). It has been suggested that invasion is limited by local factors within the deeper nucleated epithelial cells which are not conducive to fungal growth (Taschdjian et al., 1960). While such local factors may have been lost in vitro it would seem more likely that the deep penetration reflects the absence of systemic components within the culture system, as suggested by Blank et al. (1959). It is interesting to note that an intercellular permeability barrier has been demonstrated in the superficial layers of the epithelium of both skin (Schreiner and Wolff, 1969) and oral mucosa (Squier, 1973). This barrier limits the penetration of substances both into the epithelium from the surface, and outwards across the epithelium from the deeper tissues. The level to which hyphae are seen to penetrate in mucocutaneous candidiasis seems to coincide with the lower border of this barrier. It is possible that systemic factors antagonistic to Candida are present beneath the barrier and discourage fungal penetration of the deeper epithelial layers, while 

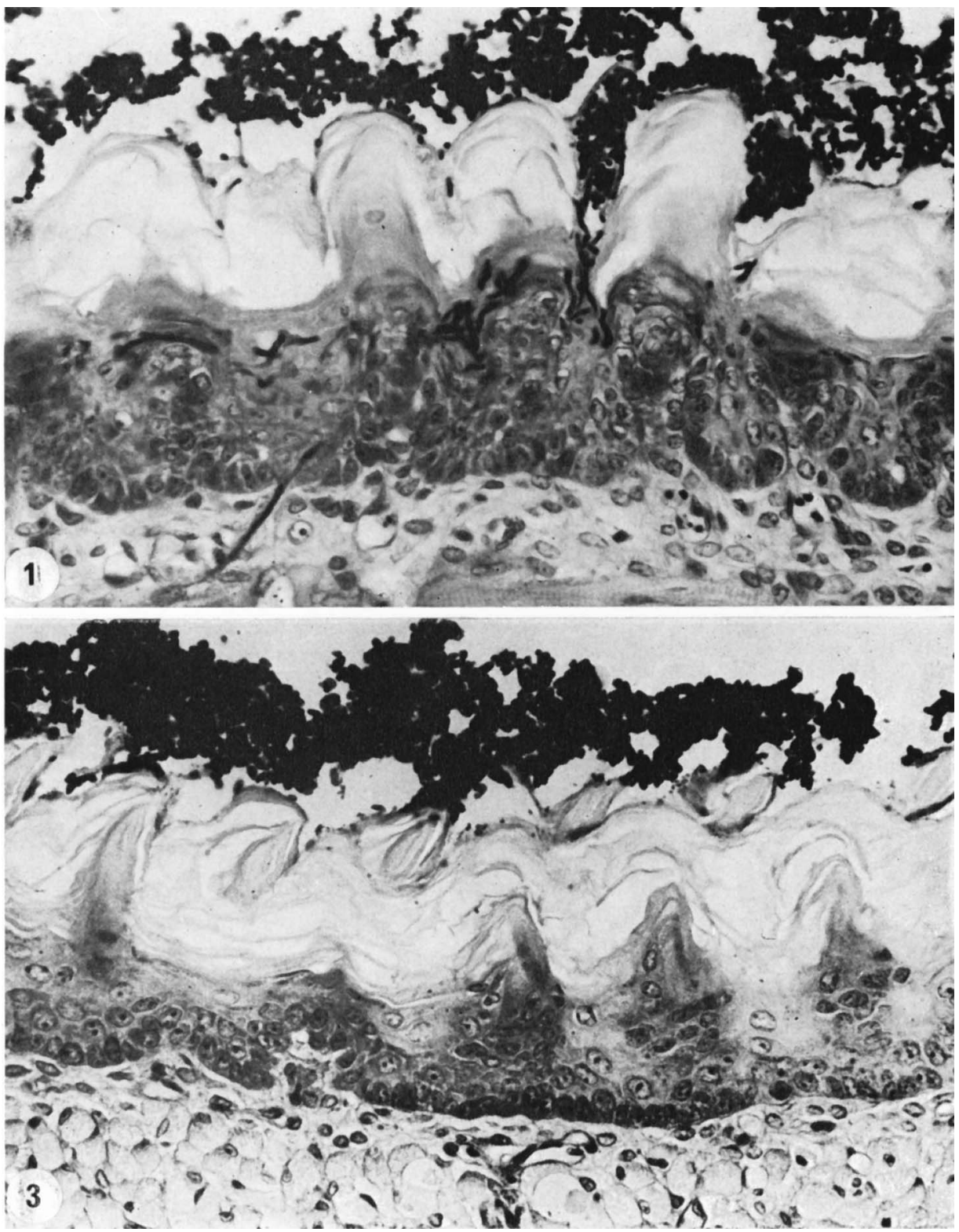

FIg. 1.-Rat tongue mucosa in vitro invaded by $C$. albicans showing blastospores proliferating on the surface of the epithelium and hyphae penetrating through the epithelial layers to the connective tissue. Periodic acid Schiff (PAS) and haematoxylin. $\times 360$.

FIG. 3.-Surface colony of $C$. tropicalis. No invasion of the epithelium is occurring. PAS and haematoxylin. $\times 360$. 

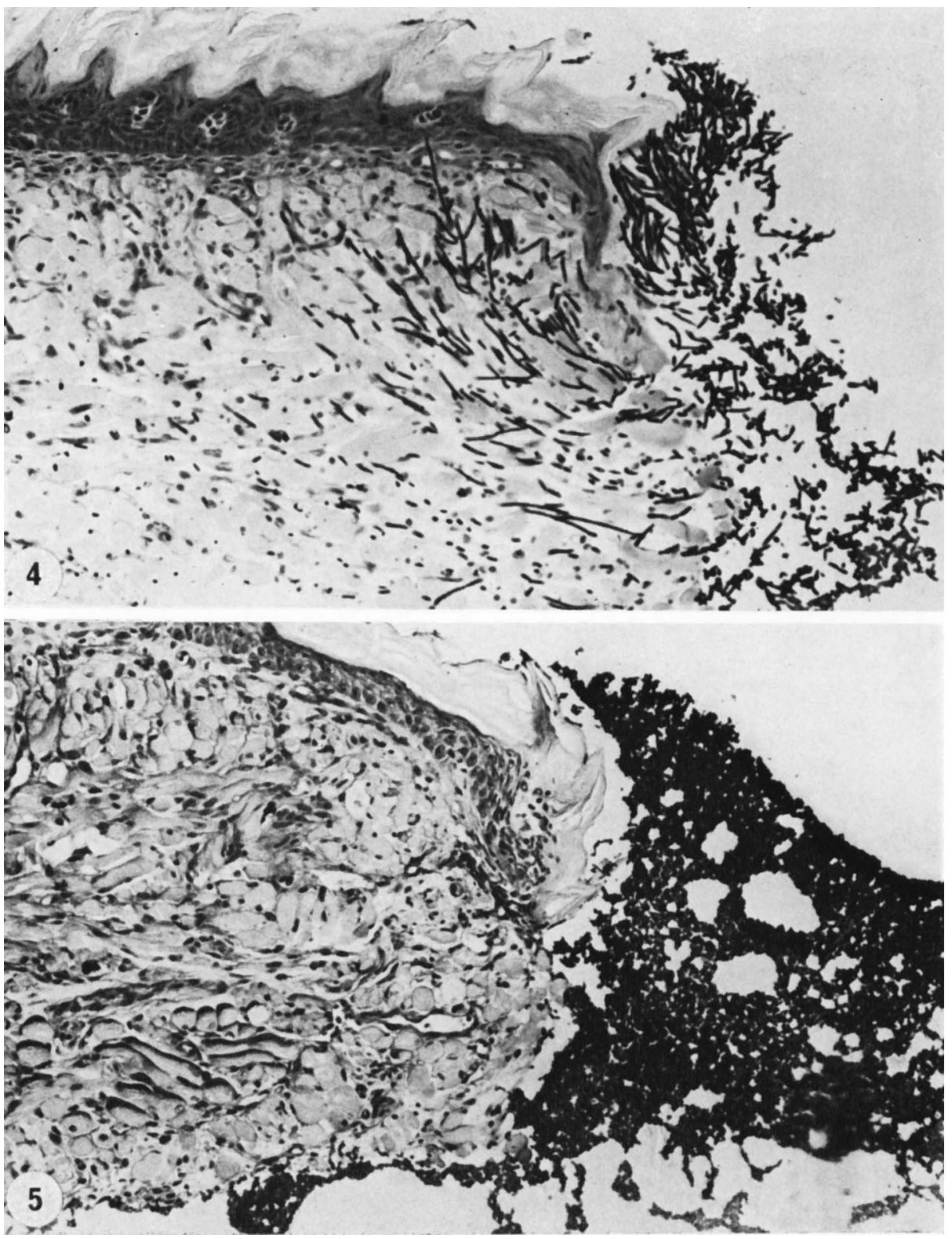

Fig. 4.-C. krusei proliferating at the side of an explant. The hyphal form is seen invading the connective tissue and penetrating the basement membrane to enter the deeper nucleated cells of the epithelium. No penetration of the stratum corneum is observed. PAS and tartrazine. $\times 140$.

FIG. 5.-A large colony of $C$. guilliermondii growing alongside an explant. No invasion of the tissue is apparent. PAS and tartrazine. $\times 140$. 
the absence of such factors in the superficial layers allows the fungus to colonise this region.

\section{SUMMARY}

Orthokeratinised mucosa from the dorsal surface of neonatal rat tongue was maintained in culture and then infected with Candida albicans, $C$. tropicalis C. krusei, C. parapsilosis or C. guilliermondii for up to $45 \mathrm{~h}$. The five species showed varying abilities to invade the tissues, which appeared to reflect their different pathogenicities. C. albicans was the only species able to invade all the tissues present, including the stratum corneum. C. tropicalis and C. krusei were able to invade connective tissue and the deeper nucleated cells of the epithelium but failed to penetrate the keratin layer, while $C$. parapsilosis and C. guilliermondii showed only slight invasion of the connective tissue. The keratin layer of rat tongue mucosa thus appeared to act as a barrier to invasion of the epithelium by anything but virulent species of candidal fungi.

The results suggest that oral mucosa in vitro retains its structural integrity and that the tissues do not act solely as a passive growth medium through which any fungal strain might proliferate. It seems that this in-vitro system is representative of the in-vivo situation and forms a useful experimental model in which to investigate the host-fungal relationship in mucosal candidiasis.

I am deeply indebted to Mr G. D. Bowden and Dr C. A. Squier for their invaluable advice and encouragement during the progress of this study. The support for this work came from a M.R.C. Junior Fellowship for which I am grateful.

\section{REFERENCES}

Blank, H., SAgami, S., Boyd, C. AND Roth, F. J. 1959. The pathogenesis of superficial fungus infections in cultured human skin. Archs Derm., 79, 524.

BudTZ-JoRgensen, E. 1971. Denture stomatitis. IV. An experimental model in monkeys. Acta. odont. scand., 29, 513.

Cawson, R. A. AND RAJASINGHAM, K. C. 1972. Ultrastructural features of the invasive phase of C. albicans. Br. J. Derm., 87, 435.

FARBMAN, A. I. 1970. The dual pattern of keratinisation in filiform papillae on rat tongue. J. Anat., 106, 233.

HowLETT, J. A. 1974. An electron microscope study of the infection of rat oral mucosa with Candida albicans. J. dent. Res., 53, 1076 (Abstract).

HuRley, R. 1966. Pathogenicity of the genus Candida. In Symposium on candida infections, edited by H. I. Winner and R. Hurley, Edinburgh, p. 13.

Hurley, R. AND STANLeY, V. C. 1969. Cytopathic effects of pathogenic and non-pathogenic species of Candida on cultured mouse epithelial cells: relation to the growth rate and morphology of the fungi. J. med. Microbiol., 2, 63.

JoNes, J. H., AND ADAMs, D. 1970. Experimentally induced oral candidiasis in rat. Brit. J. Derm., 83, 670.

JoNES, J. H. AND Russell, C. 1973. The histology of chronic candidal infection in the rat's tongue. J. dent. Res., 52, 948.

Melcher, A. H. AND Hodges, G. M. 1968. In-vitro culture of an organ containing mixed epithelial and connective tissues on a chemically defined medium. Nature, Lond., 219, 301.

Miles, A. A., MisRa, S. S. AND IRwin, J. O. 1938. The estimation of the bactericidal power of the blood. J. Hyg. Lond., 38, 732. 
Miles, A. E. W. 1974. The behaviour of the dorsal mucosa of the rat tongue in organ culture. J. Anat., 117, 541.

MONTES, L. F. AND WILBORN, W. H. 1968. Ultrastructural features of host-parasite relationship in oral candidiasis. J. Bact., 96, 1349.

Pemberton, J. ANd Turner, E. P. 1973. Organ culture model to study tissue invasion by C. albicans. J. dent. Res., 52, 948. (Abstract.)

SChreiner, E. AND WolfF, K. 1969. Die Permeabilität des epidermalen Intercellularraumes für kleinmolekalures protein. Ergebnisse elektronenmikroskopishcytochemischer Untersuchungen mit Peroxidase als Markierungssubstanz. Arch. klin. exp. Derm., 235, 78.

SQUIER, C. A. 1973. The permeability of keratinized and non-keratinized oral epithelium to horseradish peroxidase. J. Ultrastruct. Res., 43, 160.

TASChDJAan, C., Reiss, F. AND KozinN, P. J. 1960. Experimental vaginal candidiasis in mice; its implications for superficial candidiasis in humans. J. invest. Derm., 34, 89.

Trowell, O. A. 1954. A modified technique for organ culture in vitro. Expl Cell Res., 6, 246. 